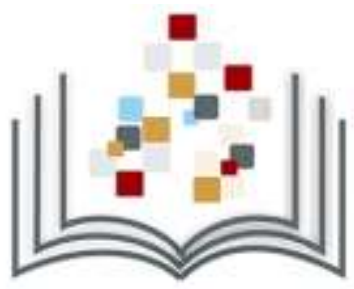

\title{
REVISTA DE JUVENTUDE E POLÍTICAS PÚBLICAS: UM RELATO DE EXPERIÊNCIA DE CRIAÇÃO E DESENVOLVIMENTO
}

Ronnie Fagundes de Brito ${ }^{1}$, Milton Shintaku ${ }^{1}$, Jaqueline Jesus ${ }^{1}$, Diego José Macedo ${ }^{1}$, Ingrid Torres Schiess ${ }^{1 *}$, Priscila Rodrigues dos Santos ${ }^{1}$, Priscila Paiva de Castro ${ }^{1}$, Andrea Maria C. S. F. Curado ${ }^{1}$, Lucas Angelo ${ }^{1}$, Lucas Rodrigues ${ }^{1}$

${ }^{1}$ Coordenação de Articulação, Geração e Aplicação de Tecnologia - Instituto Brasileiro de Informação em Ciência e Tecnologia - Brasília (DF) - Brasil

*Autor correspondente: ingridschiessl@ibict.br

\section{Como citar:}

BRITO, Ronnie F. et al.. Revista de juventude e políticas públicas: um relato de experiência de criação e desenvolvimento. In: WORKSHOP DE EDITORAÇÃO CIENTÍFICA, 9., 2016, São

Paulo. Anais... São Paulo: Associação Brasileira de Editores Científicos, 2016. p. 13-17 DOI: http://dx.doi.org/10.21452/wec.IXwec.2016.0003

\section{RESUMO}

No Brasil, o Diretório de Grupos de Pesquisa (DGP) mantido pelo Conselho Nacional de Desenvolvimento Científico e Tecnológico (CNPq) possui 299 grupos de pesquisa que estudam a juventude e áreas correlatas. Porém, há poucos canais técnicos e científicos voltados exclusivamente para disseminação de informações relacionadas às políticas de juventude no país. Assim, descreve-se historicamente a trajetória da Revista de Juventude e Políticas Públicas (RJPP), desenvolvida com o software livre Open Journal System (OJS), apoiado pelo Instituto Brasileiro de Informação em Ciência e Tecnologia (lbict), apresentando um relato de experiência das questões técnicas e tecnológicas de migração do OJS. Revela-se detalhes da migração e os problemas encontrados pela equipe. Conclui-se que a contribuição de especialistas aos processos, durante o desenvolvimento da revista, possibilitou o contingenciamento de problemas.

\section{INTRODUÇÃO}

A criação da Secretaria Nacional de Juventude (SNJ), em 2005, sinalizou a preocupação do Governo com as questões relacionadas à juventude, na medida em que essa possui grande representação na população brasileira. Com isso, a SNJ, de forma institucionalizada, promove ações, políticas e programas, de características transversais, sobre juventude.

Um destes programas tem por objetivo a participação dos jovens na construção de políticas públicas para a juventude, o Participatório. Um espaço destinado à promoção do conhecimento entre a sociedade civil e a acadêmica. No Diretório de Grupos de Pesquisa (DGP) no Brasil, mantido pelo Conselho Nacional de Desenvolvimento Científico e Tecnológico (CNPq) há 299 grupos de pesquisa registrados que estudam a juventude e áreas correlatas. Com isso, revela-se a interdisciplinaridade e transversalidade do tema.

Todavia, há poucos canais técnicos e científicos voltados exclusivamente para disseminação de informações relacionadas às políticas de juventude no país. Assim enfatiza Peralva (2007) que a questão conceitual da juventude transcende a visão 
biológica etária, numa transformação cultural, no qual os jovens aparecem como modelos de vida nova. Bem como destaca Melucci (2007) a dinamicidade de como as redes juvenis se organizam, apresentando configurações diversas, no qual novos modelos culturais, formas de relacionamento, pontos de vista alternativos são testados e colocados em prática.

Com isso, revela-se o desafio de propor, aplicar e analisar os impactos de políticas de juventude, visto ao multifacetamento do tema. Novaes (2007), Spósito e Carrano (2007) apresenta um panorama complexo voltados a políticas de juventude no país, com disputas de orientações e descontinuidade das ações, mas ainda com futuro dependente de ações governamentais.

Isto posto, reflete-se a complexidade do tema no qual está inserida a Revista Juventude e Políticas Públicas (RJPP), uma publicação vinculada à SNJ, apoiada por um projeto de pesquisa com o Instituto Brasileiro de Informação em Ciência e Tecnologia (Ibict). Um periódico técnico-científico, semestral, voltado a dar visibilidade a produção técnica e acadêmica sobre temas correlatos a políticas públicas de juventude.

Nesse contexto, o presente trabalho tem por objetivo descrever historicamente a trajetória da RJPP, desenvolvida com o software livre Open Journal System (OJS), apoiado pelo lbict. Apresentando um relato de experiência de criação e de desenvolvimento da revista, abordando as questões técnicas e tecnológicas da migração do OJS, visto a grande quantidade de revistas que utilizam a ferramenta no Brasil.

\section{METODOLOGIA}

Este estudo consiste em um relato de experiência, sem a apresentação de hipótese a ser testada. Apresentou-se a RJPP, que a partir da parceria entre SNJ e lbict, em 2015, a RJPP tornou-se uma das vertentes voltadas a gestão da informação sobre políticas públicas de juventude.

A RJPP, diferentemente da grande maioria, foi criada por meio de uma portaria, de número 32 da SNJ/SGPR, de 31 de outubro de 2014, trazendo como objetivo dar visibilidade a produção científica sobre os temas relacionados às políticas de juventude. A primeira edição da RJPP foi lançada em 16 de dezembro de 2014, contando com artigos de pesquisadores que participaram do evento da SNJ chamado "Participatório em Rede", realizado em setembro, que reuniu 100 especialistas em Juventude de todo o país. A 1a Chamada Pública ocorreu entre os dias 15/12/2014 a 30/01/2015 (com prorrogação de inscrição até o dia 31/03/2015), tendo os artigos selecionados por meio de análise da comissão de avaliação instituída pelo sistema duplamente cego.

Nos resultados e discussões, dividiu-se as questões da migração do software OJS em dois grupos: as técnicas - são relacionadas ao uso da ferramenta OJS, e as tecnológicas - são relacionadas a instalação, as configurações iniciais e as atualizações de plugins. Relata-se brevemente a migração das versões do OJS, apontando as ferramentas que auxiliam no processo e os problemas enfrentados.

\section{RESULTADOS E DISCUSSÕES}

Para o desenvolvimento da revista foi utilizado o OJS versão 2.4.5. Posteriormente, com o apoio do lbict, foi atualizado para a versão 2.4.8 (figura 1), de forma a permitir a atualização para a versão 3, lançada no final de agosto de 2016. Com isso, torna-se uma das primeiras revistas brasileiras a utilizar a última versão do OJS, que apresenta uma grande mudança na apresentação. 


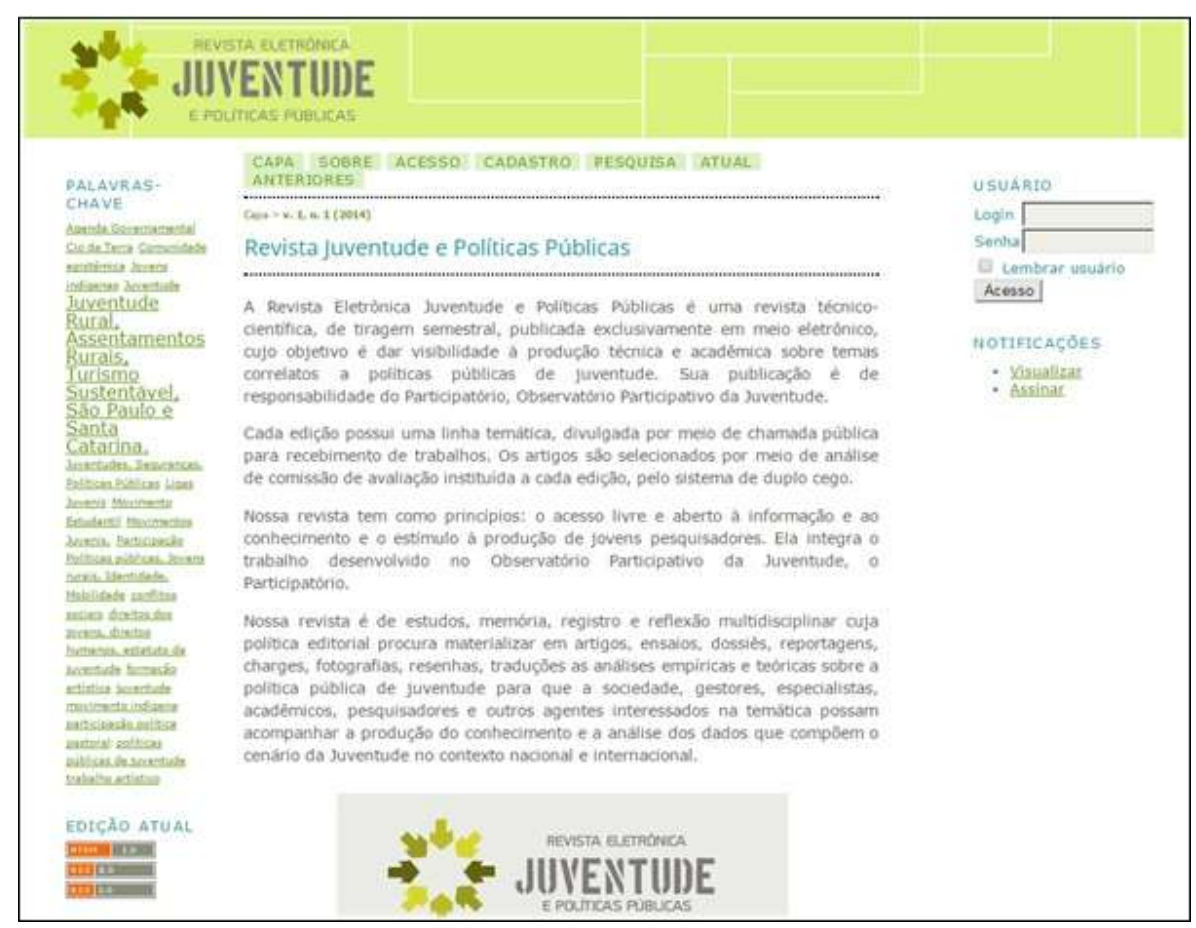

Figura 1: Revista SNJ na versão OJS 2.4.8

Fonte: Dos autores, 2016.

A migração foi efetuada por meio do script de atualização do OJS, de forma a não se perder nenhuma informação da revista, principalmente o histórico das submissões. Entretanto, durante a atualização os arquivos do fluxo editorial foram afetados, não constando na interface da nova versão. Como contingenciamento, os arquivos foram recuperados da instalação OJS 2.4 .8 e anexados manualmente na nova versão do sistema. Acreditamos que esse problema de cópia dos arquivos seja devido ao lançamento recente e relativa imaturidade do script de atualização. Apesar disso, temse a revista atualizada, apresentada na figura 2 , de forma transparente, mesmo com as diferenças significativas entre as versões 2 e 3 do OJS.

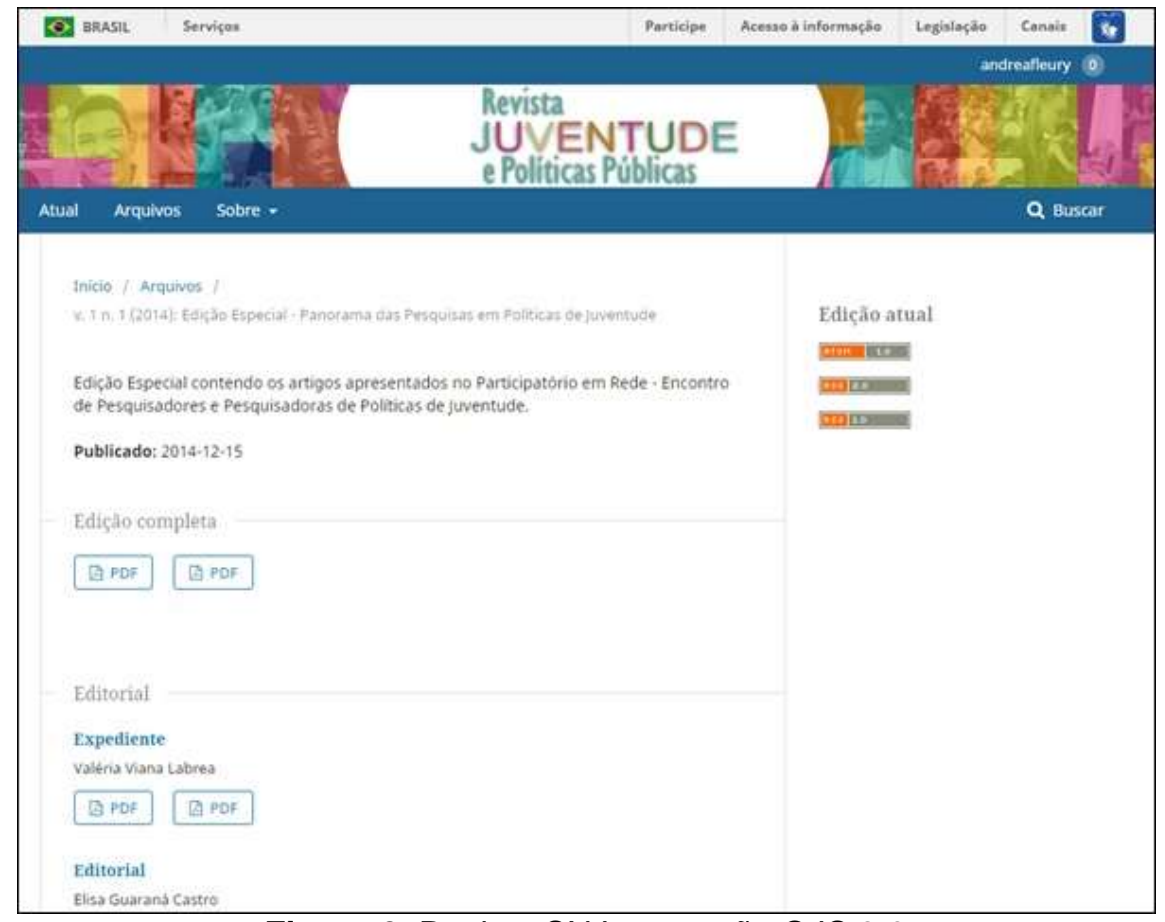

Figura 2: Revista SNJ na versão OJS 3.0 Fonte: Dos autores, 2016. 
A implantação da identidade visual, semelhante aos outros sistemas deu maior integração do periódico aos outros sistemas mantidos pela SNJ, em especial aos apoiados pelo projeto com o lbict. A versão 3 do OJS apresenta-se com estrutura diferente das versões anteriores, com usabilidade melhor que das versões anteriores.

Outro ponto de destaque é a gestão da revista, que foi acrescida de três bibliotecárias, três especialistas em informática e editor executivo operando na equipe editorial. Essa equipe foi primordial para a atualização e manutenção da revista. Todos os artigos aceitos para publicação são normalizados pela equipe, desonerando os autores no que se refere a adequação às normas da revista.

\section{CONCLUSÃO}

Revistas técnico-científicas mantidas por órgãos do governo, independente da esfera, apresenta-se diferenciada pelo alto grau de oficialização, visto não estar no centro das ações dos órgão a que são vinculados, diferentemente das universidades e unidades de pesquisa, que possui na geração de conhecimento uma das suas atividades. A RJPP não se apresenta diferente, visto pertencer a SNJ, que por sua vez está vinculado à Secretaria-Geral da Presidência da República (SGPR).

A revistas possui uma temática ampla, que permeia várias áreas do conhecimento, em que as relações disciplinares estão mais presentes. Com isso, impõe certos desafios, no que se refere ao processo de avaliação cega, pela necessidade do envolvimento de pareceristas de várias disciplinas.

Por contar com a contribuição de bibliotecárias e especialistas em informática, a revista apresentou uma dinamicidade maior, principalmente na atualização, pelo conhecimento da equipe na ferramenta OJS. Conhecimento técnico e tecnológico no OJS revelou-se primordial nesse processo de atualização, pelas diferenças apresentadas nas versões.

\section{REFERÊNCIAS}

MELLUCI, Alberto. Juventude, tempo e movimentos sociais. In: FÁVERO, Osmar et al (Org.). Juventude e contemporaneidade. Brasília: Unesco, 2007. p. 29-46. (Coleção Educação para todos). Disponível em: $<$ http://portal.mec.gov.br/index.php?option=com docman\&view=download\&alias=648vol16juvcont-elet-pdf\&category slug=documentos-pdf\&ltemid=30192 >. Acesso em: 21 set. 2016.

NOVAES, Regina Reyes. Políticas de juventude no Brasil: continuidades e rupturas. In: FÁVERO, Osmar et al (Org.). Juventude e contemporaneidade. Brasília: Unesco, 2007. p. 179-216. (Coleção Educação para todos). Disponível em: $<$ http://portal.mec.gov.br/index.php?option=com docman\&view=download\&alias=648vol16juvcont-elet-pdf\&category slug=documentos-pdf\&ltemid=30192 >. Acesso em: 21 set. 2016.

PERALVA, Angelina. Juventudes no mundo contemporâneo. In: FÁVERO, Osmar et al (Org.). Juventude e contemporaneidade. Brasília: Unesco, 2007. p. 13-28. (Coleção Educação para todos). Disponível em:

$<$ http://portal.mec.gov.br/index.php?option=com docman\&view=download\&alias=648vol16juvcont-elet-pdf\&category slug=documentos-pdf\&ltemid=30192 >. Acesso em: 21 set. 2016. 
SPÓSITO, Marília Pontes; CARRANO, Paulo. Juventude e políticas públicas no Brasil. In: FÁVERO, Osmar et al (Org.). Juventude e contemporaneidade. Brasília: Unesco, 2007. p. 179-216. (Coleção Educação para todos). Disponível em:

$<$ http://portal.mec.gov.br/index.php?option=com docman\&view=download\&alias=648vol16juvcont-elet-pdf\&category slug=documentos-pdf\&ltemid=30192 >. Acesso em: 21 set. 2016.

PALAVRAS-CHAVES: Open Journal System. Comunicação científica. Secretaria Nacional de Juventude. 